\title{
Community expectations and urban development perspectives: urban development as experienced in South Africa
}

\author{
C. B. Schoeman \& T. P. Moroke \\ Subject Group for Urban and Regional Planning, \\ North-West University (Potchefstroom Campus), South Africa
}

\begin{abstract}
The concept of a sustainable city, it seems, forms a very complex entity with many interactive components, tenant in the integrative perspective and its futuristic scope, before it can be termed to be sustainable. This being the case, how does the planning system bring the community involvement to address the challenges faced by the contemporary city? Thus, this paper analyses the present practices underlying urban development in central and the capacitation of community; to understand the activities underpinning this reality and its operating environment: assess like the threats and opportunities involved from a scientific, philosophical and political point of view. Spatial planning is in nature (and will always be) politically sensitive.

With community development in South Africa, desires and expectations are focused on the present reality: they want jobs, homes and socio-economic security and access. The research conducted in Matlosana Municipality in RSA recognised this interface and the need for interdisciplinary approach at the local level. The focus of the paper will be to establish the point at which a range of different kinds of question collide and require simultaneous solutions; and in which issues of power [governance] and community needs [involvement] can result into interdisciplinarity. This is considered the main pathway to resolve community issues and thus support towards enhancing the sustainable city principle in terms of an incremental approach towards revitalization of neighbourhoods urban integration and thus sustainability.

Keywords: sustainable city, community [involvement], capacitation.
\end{abstract}




\section{Introduction}

The complexity of the contemporary city is identified as the most challenging problem in urban development and a limitation of public participation. Such-up, the understanding of networks, reciprocal relationships and planning for integration and sustainability of a city forms a critical point of view. Perhaps the most appropriate first step to understanding the activities underlying the different dimensions of city functionality is that these components subdivide extensively getting messier and more complex. For example, in the US - the transit planning and sustainable development have transcended to on-going policy debates on mobility, lifestyle, and civic engagement, transportation which has emerged as a key site of struggle, engagement, and opportunity for diverse communities and planners alike (Bose [1]). At this juncture this paper explores, how does the planning system bring the community involvement to address the challenges faced by the contemporary city? And what is community expectations and desires in the light of urban development projects?

Thus, through these lenses, the paper begins with a review of the concept of urban development regimes - more specifically the community response to these changes. Section three looks at the case study background and method of research. Section four describes the community-based survey to determine the correlation between subjective participation and neighbourhood satisfaction. Section five presents the interpretation of the case study results effect on the participation and sustainability. Lastly, results attempt on informing the National Treasury funded Neighbourhood Regeneration Strategy to address challenges of urban areas in line with citizens' desires and expectations acting in concert over present realities: jobs, homes and socio-economic security and access.

\section{Urban development regimes and community response}

There appears that the interface between community and community development is intertwined hence, Jakaitis and Stauskis [2] argue community has been greatly influenced by the character of the environment. Misener and Mason [3] inference is that many cities around the world once benefited from industrial sectors that determined the growth, wealth, and overall economic prospects for cities. The premise behind this manifestation is straightforward: surrounding communities are reliant upon such industries for jobs, wealth and overall economic prospects. While on the due course, the historical periods of urban development marked a decline in traditional manufacturing industries and globalisation becoming a force to be recognised with in urban development of a modern city. Jakaitis and Staukis [2] affirm that urban residents have inhabited very different areas of a city ... to gain a specific type of their lifestyle.

South Africa alike is experiencing urban regime and each regime representing a particular common interest from citizens of a particular community. During the apartheid regime, the racially disintegrated spatial distribution defined economic and social interests as a response to unjust way to control resources and implement growth strategies not favouring all the citizens. How and when the 
citizens were to interact with the city was determined by authorities. However, there was paradigm shift that marked post-apartheid: focusing on economic and social transformation aligned to 'sustainable development' - enabling ecological and cultural influences in the collaborative perspective.

\subsection{Sustainable development and city sustainability}

The term sustainable development was first used in the mid 1970s (Du Plessis [4]). In position to human development patterns, the 1972 study of global resource use called The Limits to Growth by Meadows et al. [5] appears to be the most basic work of the term sustainable. The work advocates for alteration of growth trends and establishing a condition of ecological and economic stability that is sustainable far into the future. The WCED [6] definition - "development that meets the needs of the present without compromising the ability of future generations to meet their own needs" is most frequently used as the starting point for discussions on the concept of sustainable development. This ecological drive has emerged useful framework for sustainable urban development enabling assessment of the relationship between human populations and the environments in which they live and forming the policies and programmes that embrace public participation. This means realising and appreciating community strengths and assets to create new opportunities within the communities. This chime in philosophical view hence, Choguill [7] cautions that cities cannot be considered sustainable if their component parts... do not meet sustainability criteria. According to Snow [8] it translates to community transformation which goes along with a transformation of the mind. In reality the challenges might be political sensitive too on account of the land-use.

Therefore, each of these principles is seen as equally important in achieving sustainable development, especially when attempting to apply the concept in a situation such as designing more sustainable community unit. As a result, it is clearly evident that sustainability has become an important element to be considered in the planning of urban area (Choguill [7]). Therefore, the subsequent discussion focuses on sustainable development characteristics and principles recognizing explicitly its intrinsic value in dealing with issues such as poverty, inequality, environmental degradation and more in urban areas.

\subsubsection{Community development}

Community development is wide and varied concept. However, there are two trajectories that most commonly identified as the pillars of community development namely: development in community and development of community. Making a distinction Brennan [9] articulates development in community - to be associated with the recruitment or establishment of industry and other economic structures while the development of community is the establishment of relationships and networks between diverse community members (Wilkinson [10]) such as establishment of a local community council and bringing together a diverse and representative grouping of the local population. In detail in outcomes are envisioned and their achievement signals the success and end of development. Then there is issue of interaction, the most 
obvious being social and economic interaction. The interaction broadens as sustainability is framed in ways that all its dimensions prioritize environment.

Therefore, community development is indivisible concept that requires conceptual framework for it to fit in the settings of different communities. According to Helling et al. [11] it is necessary to have an institutional framework enabling, supporting and/or prescribing the procedures to be followed in the process to allow effective and meaningful public engagement. This approach looks for results ... to the neighbourhood as a whole (Wilkinson [10]). Its first business is to survey its field, to find out what needs to be done. Then it seeks to make contacts - to get in touch with all the elements that go to make up the social life of the neighbourhood, to organize and correlate the neighbourhood forces for good, that conditions may be improved for all (Helling et al. [11]).

\subsubsection{Community participation}

Citizen involvement in neighbourhood planning is known as collaborative planning process and it addresses current issues and establishes future goals at a detailed level (Kelly and Becker [12]). In most situations, neighbourhood planning has been found to work best within the framework of a city's comprehensive plan (Kelly and Becker [12]). This means empowering the citizens with adequate support and resources to find their own solutions to the problems they identify in their own communities. This planning brings together multiple city departments, community organizations, citizens, local stakeholders, and social service providers to coordinate their efforts to deliver a wide range of quality services at the neighbourhood level and to provide a more responsive, interactive environment for residents to express their concerns and needs. In most cases, plans for land use, economic development, housing, and transportation are executed without engaging the communities that will be impacted by the plan.

Highlighting the importance and effectiveness of citizen participation, Das and Takahashi [13]) argue that as a consequence of decentralization, slum upgrading transformed from a highly state-controlled activity in the early 1980s to a much more participatory development activity by the late 1990s, where communities, often aided by NGOs as facilitators and intermediaries, participate at various stages of a project - identification, design, financing, construction, and maintenance. Community architecture has the promise of good design because it meets the requirements of users, fulfils their lifestyles, and carries the essence of their desires/expectations.

2.1.2.1 Urban communities basic interest In reviewing considerable related foreign and domestic literature, implicate the introduction of development projects into communities being the most challenging especially when appropriate participation of the local community and stakeholders has not been properly brought on board (Snow [8]), resulting in: what is in it for me? Perhaps the most appropriate first step to understanding this line of reasoning is that community needs and expectations are core activities. In the words of Jakaitis and Stauskis [2] drawing in Germany experience, the basic interests that local 
urban communities have in the surrounding territory cove the areas of high quality residential environment and its architecture: proper spatial arrangement of the territory, well-developed services, including social services, equally distributed working places and good opportunities for employment and labour, easily accessible primary health care and child care, primary and secondary education, recreation and leisure, safety and security, maintenance of territories and equal opportunities for local mobility.

In South Africa, incidents illustrate community interest(s). The protest wave that was hitting different parts of the country varying from protest to protest and community to community is recognized to have started in 2004 (Nleya [14]) and consistently resurfacing whenever the poor urban dwellers are having a grievance are housing, water, sanitation and electricity explicitly illustrate their deficit in service delivery (Nleya [14]). In exploring the dynamics of community interest this simply say community citizens are denied a platform in the matters that directly have effect on them. Concerting to much of the literature the reality reflects messiness as decision without community participation transcending to be partial solutions and most threatening to blow up.

There appears to be a strong negative attitude and rejectance towards the projects that ignore communities' values and interests as well as the spatial patterns. The subsidy housing policies assumed that all housing consumers, from shanty-town and capitalists alike, have more or less the same interests and can be served by more or less the same policies. For example, the Mogale City Municipality residents in Johannesburg prefer the village-like settlements rather than the township setting. What transpired is that the people rejected the house as the project subsidy framework was not in line with their needs. Thus, in order for development to truly have an effect on community; values about space and communities needs have to be respected.

\section{Methodology}

\subsection{Research objectives}

The main research objectives are based on establishing the interface between community citizens and community development. Thus, the overall aim of this paper is to investigate the following objective: (1) analysing the present practices underlying urban development in central and public participation reflecting on the capacitation of community; (2) understand the activities underpinning urban planning and its operating environment: assess like the threats and opportunities involved from a scientific, philosophical and political point of view; (3) determine city-wide monitoring system for neighbourhood development and build sustainable partnerships to foster integrated urban-neighbourhood development. In this sense, where the system has deviated from what is existing theory and practices and expectations, corrective action be taken into account in the light of spatial impacts of visual fragmentation, integration and sustainability; (4) notwithstanding various attempts and claims to incorporate community - the urban regeneration strategies and community development is examined how it 
echoes on the development of social infrastructure in communities. In essence, the basic knowledge and understanding of the urban spatial system will translate to a city with interactive habitants; a community that knows and understand the dynamics that could reverse the negative effects through sustainable application.

\subsubsection{Case study and research strategy}

This paper is largely an interpretative examination and analysis of the strategic approaches that form the basis of sustainable integrated neighbourhoods and human development. The study has examined the theoretical literature in order to understand ground theories and examine how development project were implemented and the role of citizens in those projects. The pressing issues and gaps identified in the formal and informal locations were analysed. Hence, the study has traced the conceptual roots of township developmental profile through sustainable urban development and its source concept: sustainable development, measuring the satisfactory component of neighbourhood quality indicators and considering the spatial analysis to reflect the realities of the study area.

3.1.1.1 Empirical data gathering: this paper has drawn on range of empirical methodologies such as structured interviews and case study. The case study was selected on the basis of National Development Partnership Grant (NDPG): (1) township struggling to achieve urban integration and sustainable urban development; (2) consisting mostly of residential units without/few community facilities or commercial activities and several vacant stands; (3) the Integrated Development Plan (IDP) must have identified community development need.

3.1.1.2 Sample: the field visits were carried out for visual inspection and preliminary enquiries. The face to face interview was used to collect data using a standardized questionnaire. The MLM population consisted of 385,782 households of which the townships constitute 70,526 households from which the researcher selected a sample of 654 respondents as the focus of the study is on townships using the 0.9 per cent procedure. All 654 households' representatives were interviewed from all the five townships as shown in table 1 below. The researchers used systematic random sampling technique to select the respondents from each township based on the number of households per township.

The researchers selected one household randomly from among the first eight through the 'lottery technique', and then select the next households based on the interval established. In essence, a determination and analysis of these types of neighbourhoods is based on naturally occurring clusters of data in space. The neighbourhoods resulting from this analysis are not discretely bounded neighbourhoods but places with similar land use, housing density, and local accessibility characteristics within a predefined size of a circular or square neighbourhood. A circular neighbourhood with a $2 \mathrm{~km}$ radius or 30 minutes' walk, as it represents the traditional planning field definition of "neighbourhood" for easy walking distances to destinations in the South African context will be used to draw the sample population. The provision was made for cluster analysis 
with a neighbourhood size of more than $2 \mathrm{~km}$ radius to produce more representative region based sample as most of low income neighbourhoods were observed not to fall under the typology during pre-survey evaluation through examining aerial photographs, and comparing neighbourhood boundaries with respect to the STATS SA Community Survey 2007 and Google Earth Maps.

Table 1: $\quad$ Townships’ proportional interview respondents.

\begin{tabular}{|l|c|c|c|}
\hline Townships & $\begin{array}{c}\text { Number of } \\
\text { households }\end{array}$ & $\begin{array}{c}\text { Percentage per } \\
\text { township households }\end{array}$ & $\begin{array}{c}\text { Number of households } \\
\text { interviewed per township }\end{array}$ \\
\hline Jouberton & 28,509 & 41 & 268 \\
\hline Kanana & 20,717 & 29 & 190 \\
\hline Khuma & 13,553 & 19 & 39 \\
\hline Alabama & 3,928 & 6 & 33 \\
\hline Tigane & 3,819 & 5 & \\
\hline
\end{tabular}

\subsubsection{Variables used in the analysis}

The research findings of the study are presented using the tools for data analysis that involve statistical significance and correlation coefficient to model the present study overall neighbourhood satisfaction as it determined by a set of neighbourhood quality measures (such as economical and appropriateness as a place to live in, involvement and availability of things to do and sense of neighbourhood as home), in an effort to recognise the critical links to establish sustainable livelihoods strategy.

The decision for rejecting or not rejecting the null-hypotheses was conducted based on the p-value determined. The study data types are nominal and ordinal resulting in application of different correlation coefficients. Whereby; the Phi Coefficient denoted $(\varphi)$ computes the correlation between two nominal variables in general and also in the special case of dichotomous variables while Spearman's rank correlation denoted rho $\left(r_{s}\right)$ computes the correlation between two ordinals variables in which its categories are ranked. These results were used to determine the magnitude of community involvement and practical significance to interpret the study objectives of sustainable community development process.

\section{Case study survey results and modelling}

In this section the study seek to find out whether research objectives are met through the level of neighbourhood satisfaction to determine citizens' participation as one of sustainable city prominent advocacy for sustainability. The interface between community citizens and neighbourhood development is another important consideration the study seeks to find; how the set of 
neighbourhood quality measures factored in this study have reflected on it as it assumed to would be critical in informing policymaking and decision making.

Reasons to reside in a neighbourhood: the respondents were asked to reveal the main reason why they have decided to locate in their respective locations from born here, married here, job opportunities, low crime rate, has all I wish for, opportunity to save, close to amenities and nowhere else to go. It is assumed that this question inquisitiveness into choice of location to some extent will exercise some control over level of participation in matters that affect the community. The association between the two sets of rank scores is investigated through the following hypotheses:

$\mathrm{H}_{0}$ : There is no correlation between neighbourhood satisfaction and reasons to reside in a neighbourhood.

$\mathrm{H}_{\mathrm{a}}$ : There is a correlation between neighbourhood satisfaction and reasons to reside in a neighbourhood.

Table 2: $\quad$ Phi coefficient correlation $(\varphi)$ choice of location.

\begin{tabular}{lc|c}
\hline & Value & Approx. Sig \\
\hline $\boldsymbol{\varphi}$ & .329 & .000 \\
$\mathbf{N}$ & 644 & 644 \\
\hline
\end{tabular}

The results show statistical significance and a coefficient value $\varphi=0.329$. In this case, $\varphi$ is a weak positive relationship between the two variables. The results although had weak positive correlation, they are highly significant $\mathrm{p}=.000$ $(\mathrm{p}<0.05)$; there is a very strong evidence to reject $\mathrm{H}_{0}$, indicating that these variables are likely to be important factors in the regression models. The correlation of these two variables is in the same direction. This demonstrates the linear relationship that hinges on neighbourhood satisfaction as an important feature of sustainable communities and an indication of participation.

Sense of neighbourhood: the respondents were asked questions that would illustrate on sense of neighbourhood (namely on level of working together, neighbourhood willingness to help their neighbours, close-knit of neighbourhood and level of neighbourhood values) within 15/20 minutes walking distance. The main purpose of asking these questions to draw the subjective perceptions of respondent's potential to collaborate and participate meaningfully. The hypothesis derived from these variables would be:

$\mathrm{H}_{0}$ : There is no correlation between neighbourhood satisfaction and sense of neighbourhood.

$\mathrm{H}_{\mathrm{a}}$ : There is a correlation between neighbourhood satisfaction and sense of neighbourhood.

The results are statistically significant, meaning that $\mathrm{p}<0.05$ for all the variables, and then reject $\mathrm{H}_{0}$. The highest correlation $\left(r_{s}=.580\right)$ was obtained between enjoyment and level of working together (within 15/20 minutes walking 
Table 3: $\quad$ Spearman's rank correlation (rho $\left[r_{s}\right]$ ) sense of neighbourhood.

\begin{tabular}{lcccc|cccc}
\hline & \multicolumn{3}{c}{ Value } & \multicolumn{5}{c}{ Approx. Sig } \\
\hline $\mathbf{r}_{\mathbf{s}}$ & .580 & .476 & .449 &.-244 & .000 & .000 & .000 & .000 \\
$\mathbf{N}$ & 575 & 628 & 616 & 535 & 575 & 628 & 616 & 535 \\
\hline
\end{tabular}

distance), followed by neighbourhood willingness to help their neighbours $\left(r_{s}=.476\right)$, close-knit of neighbourhood $\left(r_{s}=.449\right)$, and the lowest was with level of neighbourhood values $\left(r_{s}=-.244\right)$. Of the four variables found to be significant, three had moderate positive correlation, only one had a very weak negative correlation although remained significant; meaning it affects the ability to participate. The negative correlation indicates that this variable is likely not to be important factor in the regression models. Interestingly, it is statistically significant like other variables, which means it is variable that can be used in community development.

Level of neighbourhood involvement: the households were asked to indicate whether they had taken part in a consultation about local services or problems in their area in the last 12 months by completing a questionnaire, attending a public meeting and being involved in a group set up to discuss local services problems. The variables were used to reflect underlying realities on neighbourhood participation and their perceptions in the trends or patterns of information dissemination. The study assumed that the level of neighbourhood involvement will be a critical factor in reflecting interface and the need for interdisciplinary approach. The hypotheses were set out as follows:

$\mathrm{H}_{0}$ : There is no correlation between neighbourhood involvement in municipal activities and neighbourhood satisfaction.

$\mathrm{H}_{\mathrm{a}}$ : There is a correlation between neighbourhood involvement in municipal activities and neighbourhood satisfaction.

Table 4: Phi coefficient correlation $(\varphi)$ level of neighbourhood involvement.

\begin{tabular}{llll|lcc}
\hline & \multicolumn{3}{c|}{ Value } & \multicolumn{3}{c}{ Approx. Sig } \\
\hline $\boldsymbol{\varphi}$ & .056 & .102 & .097 & .035 & .033 & .048 \\
$\mathbf{N}$ & 654 & 654 & 653 & 654 & 654 & 653 \\
\hline
\end{tabular}

The results are not statistically significant; (completion of a questionnaire $[\mathrm{p}=.035]$; attendance of public meetings $[\mathrm{p}=.033$ ] and task team involvement $[\mathrm{p}=.048])$. All these variables had the $\mathrm{P}>0.05$ as computed from the sample data, then we fail to reject $\mathrm{H}_{0}$. The relationships between neighbourhood satisfaction and involvement in municipal activities were determined and based 
on the logic of correlations. Table 3 shows the coefficients obtained; the highest correlation $(\varphi=.102)$ was obtained between satisfaction and attendance of public meetings, followed by involvement in group set up to discuss local services problems with correlation $(\varphi=.097)$ and the lowest was completion of a questionnaire $(\varphi=.056)$. The strength of relationship is very weak and negligible. However, the subtle difference between $(\varphi=.102)$ and $(\varphi=.097)$ indicates the consistency and leverage the perception that involvement in municipality activities has little to do with satisfaction. Community meetings deem critical to participation as it relates to satisfaction as it is also mostly statistically significant variable; this means it is the most determining factor in this model. However, the other two variables are still important determinants because as neighbourhood involvement increases then satisfaction increases too.

\section{Interpretation of research results}

The key finding of this study reveals that all variables are statistically significant indicators of subjective neighbourhood satisfaction as it exercises some control over level of willingness to engage in matter that affect the community development. Hence, the paper is based on the evidence presented on the correlated nature of neighbourhood satisfaction and neighbourhood participation control measures. The breakdown of the discussion is presented as follows:

Reasons to reside in a neighbourhood: a significant relationship exists between neighbourhood satisfaction and reasons to reside in a neighbourhood. What this result has shown is acquiring inquisitiveness nature into how the choice of location to some extent will exercise some control over level of willingness to engage in those matter that affect the community. As a result its weak positive correlation coefficient shows that to some extent it can be an influential factor in determining the level of involvement. This suggests that the quality of physical and social environment as well as economic opportunities to a certain level fulfil the intentions of residents in choosing to live in the neighbourhoods and these characteristic may also affect the level of interest in neighbourhood activities. The satisfaction level to a place is thought to be governed by a wide range of factors including both social and physical attributes of the residential environment. Lovejoy et al. [15] have found that safety, good design and appearance of houses are the most important features for neighbourhood satisfaction. Therefore, the reason for a weak positive coefficient value $\varphi=0.329$ is not far-fetched, given the South Africa's historical pattern of racial segregation. The study postulate that it has led low levels of satisfaction as location was and is still determined by authorities in poor communities. Nevertheless, the findings would be an important determinant of neighbourhood satisfaction especially in the informal settlement. The nature of townships and the location dynamic make the satisfaction perceptions complex.

Sense of neighbourhood: results show that a significant relationship exists between perceived sense of neighbourhood measuring indicators that are drawn to illustrate potential of participatory and subjective neighbourhood satisfaction within 15/20 minutes walking distance. It could be said that the results illustrate 
the fulfilment of possibilities of community involvement but relatively, the correlation $\left(r_{s}=.580\right)$ was obtained between enjoyment and level of working together, followed by neighbourhood willingness to help their neighbours $\left(r_{s}=\right.$ .476), close-knit of neighbourhood $\left(r_{s}=.449\right)$. In essence, it could be said that the neighbourhood size and immediate closeness of neighbours are good indicators of social sustainability and willingness to participate in community activities. While the level of neighbourhood values $\left(r_{s}=-.244\right)$ could mean the ability to participate is not viable. In support, Ge and Hokao [16] point out that individual with a varied cultural background may live in a neighbourhood and yet not share similar views. The diversity of personal senses of looking at things as well as the varied lifestyles, people's demands, preferences and evaluations of their neighbourhood environment are equally becoming more diversified.

Level of neighbourhood involvement: results show significant relationship exists between perceived level of neighbourhood involvement indicators and subjective neighbourhood satisfaction. However, based on the adopted $\alpha$ of 0.05 , significant results: completion of a questionnaire [p $=.035]$; attendance of public meetings $[p=.033]$ and task team involvement $[p=.048]$ declared a minimal effect has been demonstrated. This occurs if the significant results are too close to the adopted $\alpha$ of 0.05 such task team involvement [p $=.048$ ] as large [p > 0.05] demonstrate that if there is an effect, it was too small to be detected maybe with an experiment this size. Interestingly, the correlation coefficient: completion of questionnaire $\varphi=.102)$, attendance of public meetings $(\varphi=.102)$ and task team involvement ( $\varphi=.097)$ indicates very weak values of correlation.

The characteristics of this data, in particular the statistical effect size reflects on the quality of community participation and acceptance or rejectance of urban development project. This means that public opinion, perception and satisfaction are the often key motivating factor for successful acceptance of urban renewal project. Similar logic suggests that public acceptance has played an important component in power plant development (Chesoh [17]). The study therefore, presumes that community involvement is the fundamental feature of urban regeneration strategy and the fabric of sustainable development as it interact with all dimensions of sustainability. The concept of community perception and satisfaction are often discussed as subjective social indicators in sociological research (Chesoh [17]). The concept of community participation is therefore interdisciplinary phenomena and its collaborative character makes it procedural. The most common rational put forth is that process and planning consider and address current issues and establish future goal.

\section{Conclusions}

The premise behind the notion of public participation and neighbourhood satisfaction has fulfilled the objective of this study. Obviously, the statistical effect size of this data demonstrates that this community participation on urban renewal projects will be minimal. Perhaps what this study characteristic suggests is that the most appropriate first step might be to understand the nature of community the development ought to happen instead of set of standards. 
In the context of sustainable development, it is important also that policy makers understand the desires of society and various interest groups and various interpretations of spatial composition quality indicators. The study has proven that people do not share similar values/views although they are within the same area/township. The policy makers/researchers must ensure that the community understand the networks, reciprocal relationships to develop social infrastructure in communities. As a result the community basic understanding of urban metabolism and points of interaction and experts' identification of coordinates points per a variable [policy] where massive impact is anticipated need be considered when also delivering transformation change and making sure that a vision of the big picture is being understood.

\section{References}

[1] Bose, P. S., Building sustainable communities: Immigrants and mobility in Vermont. Research in Transportation Business \& Management, 7, pp. 8190, 2003.

[2] Jakaitis, J. and Stauskis, G., Facilitating sustainable development of urban landscape by involvement of local territorial communities in Vilnius city. Town Planning and Architecture, 5, pp. 105-111, 2011.

[3] Misener, L. and Mason, D. S., Creating community networks: Can sporting events offer meaningful sources of social capital? Managing Leisure, 11, pp. 39-56, 2006.

[4] Du Plessis, C., Analysing the sustainability of human settlements in South Africa: Challenges and methods. www.sustainablesettlements.co.za, 2002.

[5] Meadows, Donella, Meadows, Dennis, Randers, J. and Behrens, W., The limits to growth. Universe Books: New York, 1972.

[6] WCED (World Commission for Environment and Development. Our common future. Oxford: Oxford University Press, 1987.

[7] Choguill, C. L., Insufficient attention on township areas: Developing sustainable neighbourhoods. Habitat International, 32, p. 41-48, 2008.

[8] Snow, L. K., Community transformation: Turning threats into opportunities. Asset Based Community Development Institute, Institute for Policy Research: Northwestern University, 2011 Online.

[9] Brennan, M. A., IFAS community development: Toward a consistent definition of community development. 2009. Online. http://edis.ifas.ufl.edu.

[10] Wilkinson, K., The Community in rural America. New York, NY: Greenwood Press, 1991.

[11] Helling, L., Lerranno, R. and Warren, D., Linking community empowerment, decentralized governance, and public service provision through a local development framework. www.siteresources.world bank.org/INTCD/.2005.

[12] Kelly, E. D. and Becker, B., Community planning: An introduction to the comprehensive plan. Island Press, 2000. 
[13] Das, A. K. and Takahashi, L. M., Evolving institutional arrangements, scaling up and sustainability: Emerging issues in participatory slum upgrading in Ahmedabad, India. Journal of planning education and research, 29(2), pp. 213-232, 2009.

[14] Nleya, N., Linking service delivery and protest in South Africa: An exploration of evidence from Khayelitsha. Africanus, 50(1), pp. 3-13, 2011.

[15] Lovejoy, K., Handy, S. and Mokhtarian, P. Neighbourhood Satisfaction in Suburban versus traditional environments: An evaluation of contributing characteristics in eight California neighbourhoods. Landscape and Urban Planning, 97, pp. 37-48, 2010

[16] Ge, J. and Hokao, K., Research on residential lifestyles in Japan cities from the viewpoints of residential preference, residential choice and residential satisfaction. Journal of landscape and urban planning, 78, pp. 165-178, 2006.

[17] Chesoh, S., Community perception, satisfaction and participation toward power plant development in Southernmost of Thailand. Journal of Sustainable Development, 3(2), pp. 84-88, 2010. 